\title{
The Synergy in Circular Economy
}

\author{
Ineta Geipele* \\ Institute of Civil Engineering and Real Estate Economics \\ Riga Technical University \\ Riga, Latvia \\ Ineta.Geipele@rtu.lv
}

\author{
Yanis Wirzhbitskis \\ Faculty of Economics and Management \\ Latvian University \\ Riga, Latvia \\ janis.virzbickis@lu.lv
}

\author{
Kaspars Plotka \\ Department of Territorial Development Management and \\ Urban Economics \\ Riga Technical University \\ Riga, Latvia \\ Kaspars.Plotka@rtu.lv
}

\author{
Janis Zvirgzdins \\ Institute of Civil Engineering and Real Estate Economics \\ Riga Technical University \\ Riga, Latvia \\ Janis.Zvirgzdins_1@edu.rtu.lv
}

\begin{abstract}
Synergy is interaction of two or more system elements that produce a combined effect greater than the sum of their separate effects. The additional effect or the difference that is created from such an interaction is called synergy effect or synergistic effect. A system can be economical, technical or others.

The effect of synergy can be both positive and negative. The positive synergy is sometimes expressed as ' $2+2=5$ ' effect or ' $1+1=3$ ' effect, negative synergy is expressed as ' $2+2<4$ ' effect. The negative synergy effect is called dissynergy, zero synergy effect or asynergy.

The global population is growing and it has an impact on the environment. In connection with the limited resources and the not limited human needs, it is necessary to save resources. To ensure that there are enough food, water and wealth in future, we need to switch from a linear to a circular economy. The goal is to ensure healthy and safe living and working conditions and cause less harm to the environment.

The highest synergy is identified between green economy and circular economy, which can provide sustainable development in an urban environment and rural areas. Additionally, all of these relations are part of geoeconomics.
\end{abstract}

Keywords-Synergy; Circular economy; Green economy; Geoeconomics

\section{INTRODUCTION}

Global population growth, fluctuations in the multi-level governance process in the global economy, unequal growth of cities and regions create destructive future projections. Global urbanization affects economic processes in certain sectors of the economy at local, regional, national and global levels, which can affect sustainability indicators. One of the most discussed topics among the scientists nowadays is global warming, also referred to as climate change, which destructive consequences can rapidly influence the living conditions and human well-being in the coming decades.

In the $21^{\text {st }}$ century the role of environment and ecology is becoming increasingly important. Water and air pollution,

Synergy is interaction of two or more system elements that produce a combined effect greater than the sum of their separate effects. deforestation, desertification are problems that are directly and indirectly influencing the standard of living for a huge part of population worldwide. The global population is growing and it has an impact on the environment. In connection with the limited resources and the not limited human needs, it is necessary to save resources. To ensure that there are enough food, water and wealth in 2050, we need to switch from a linear to a circular economy. The goal is to ensure healthy and safe living and working conditions and cause less harm to the environment. For a long time, our economy has been 'linear'. This means that the raw materials are used to make the product, and all waste is discarded after use. In the recycling economy, materials are being reused. Economists, scientists and society seek for an alternative economic model, in which the environmental aspects are priority and decreasing the provided damage to the environment is the main objective.

Current economic models are not targeted towards protecting the biggest treasure of planet Earth - the biodiversity - and it should be changed, which could be done using the features of circular economy concept. The highest synergy is identified between green economy and circular economy, which can provide sustainable development in an urban environment and rural areas. Additionally, all of these relations are part of geoeconomics, which all together create synergy effect.

The concept of economic synergy was introduced by an American economist I.Ansoff [1], defining cooperation of multiple businesses as the economic base of synergy that is capable of exceeding the sum of results of individual companies.

Term 'synergy' originates from Greek language: oúv -

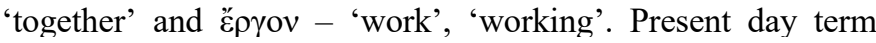
comes from Latin word 'synergia', that was first used in 1657 in theology [2]. It was introduced as a medical term in 19th century. Sir C.S. Sherrington, the Nobel Prize recipient (1932), used it in neurophysics in 1896 [3]. The term became widespread in 1925. It has been used in business and commerce since 1950s. Synergy allows realizing greater effect without utilizing additional resources. 


\section{THE CHALLENGES OF CIRCULAR ECONOMY}

The society nowadays lives from what the earth and the economy have to offer us: we use raw materials to provide us with food, shelter, clothing, heating, electrical devices and mobility. At the same time, society wastes plenty of raw materials, thus unnecessarily losing the value they have for us, polluting the environment and impacting the climate. It is estimated that by 2050 there will be more than nine billion people on Earth that will need sufficient amounts of food and clean water. They will also want to live in good health, in safety and in prosperity within the limits that our planet can bear [4].

The last 150 years of industrial evolution have been dominated by a one-way or linear model of production and consumption in which products are produced from raw materials, sold, used and discarded as waste. This model has been successful in providing affordable products to consumers worldwide. In developed economies, it has largely displaced traditional economy that featured more regeneration and reuse but required more labour resources and produced lower revenue on investment (ROI). While there is still space for linear model to expand and achieve higher efficiencies, there are signs coming decades will require productivity gains and quality improvements. As the global middle class more than doubles in size up to almost 5 billion by 2030, consumption and demand after materials will rise accordingly, rising input costs and price volatility at a time when access to new resource reserves is becoming more expensive and challenging [5]. Modern circular and regenerative forms of consumption is a promising alternative.

The beginnings of circular economy concept can be found back in 1966, when American economist Kenneth Ewart Boulding drew an analogy regarding rather circular than linear flow of material resources. It reflected a transformation from 'cowboy economy', which characterises with endless resources and ability to abandon problems, to 'spaceship economy', where limited resources had to be reused and recycled as precondition to sustainable life-support systems [6]. Circular economy can also be described as a concept linked with the idea of closed-loop systems and economies, where wastes are put back into the system to become resource inputs for production processes. For the circular economy to become reality, important factors are knowledge accumulation, progress control and assurance to supply policymakers with data and information, and to assure sufficient comprehension for the ability to develop supportive and elastic policies. The circular economy requires careful management of material flows.

The need for circular economy is promoted by the need to achieve sustainable development goals over the next 15 years to address critical areas - poverty, hunger, clean water (people), sustainable consumption and production, environmental conservation, climate changes (planet), inclusive economic growth, affordable and clean energy, sustainable cities and communities (prosperity) [7].

\section{CHARACTERISTICS OF CIRCULAR ECONOMY}

The main features of circular economy are:

1. designing out waste;

2. building resilience through diversity;

3. shifting to renewable energy sources;

4. thinking in systems;

5. thinking in cascades [5].

While circular economy examples are limited in geographical scope, estimated global savings potential of the circular economy to be approximately 700 billion USD in global consumer goods material savings alone. An income stream for investors and municipalities can be generated by collecting household food waste for biogas and compost production meanwhile giving cities and regions a new source of revenue. Additional profit can be created for brewers by selling the spent grains to the farmers in fish farming and livestock sectors thus 'cascading' it to another industry. 190\% revenue can be made in the United Kingdom, if the garments were sold are current prices. This example reflects the features of synergy effect, creating a space for 'green' entrepreneurship and providing jobs thus decreasing the unemployment rates. A cost reduction of $20 \%$ can be achieved by shifting from disposable to reusable glass beer bottles, which could be used up to 30 times as currently achieved in Germany. That would lower the costs of packaging, processing and distribution [5].

Fig. 1 illustrates synergies for creating integrated value. It reflects five economic trends - resilience economy, digital economy, access economy, circular economy and well-being economy - creating Nexus economy. That can be characterised as a synergy of five future economies worldwide.

However, this circular approach lacks scaling, which means that only a small percent of companies worldwide use these features. Solution might be governmental support by subsidies or other beneficial means for companies, because entrepreneurs mainly make their decisions based on monetary indicators.

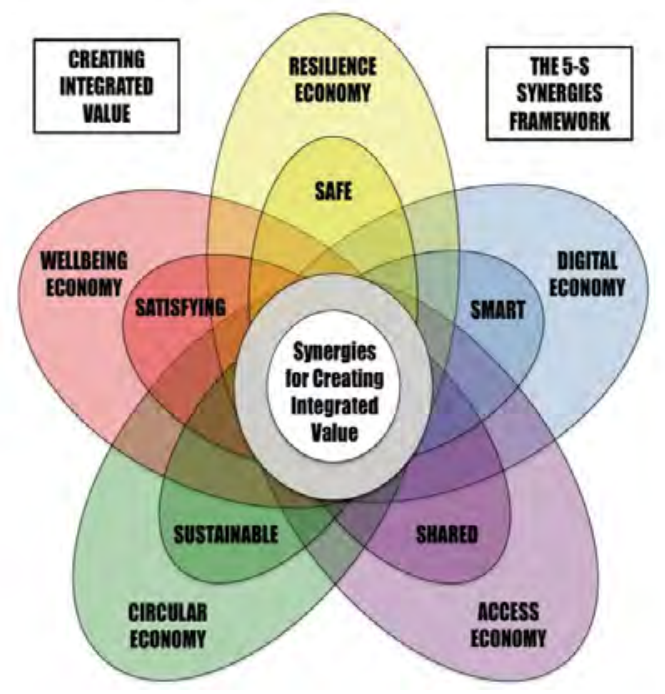

Fig. 1. Synergies for creating integrated value framework [8]. 
Circular Economy means considering more than just waste management. In any case agriculture, water, soil, biodiversity and other aspects have to be considered. But the most important area is energy. A resource efficient society only can be achieved by introducing a sustainable energy supply alongside the resource and environmental protection strategy [9]. The reports about worldwide status of circular economy might not be correct. Theoretically a $100 \%$ recycling society is possible no matter to what extend we include eco design and avoidance or sufficiency strategies. But energetically seen many recycling technologies or processes are not possible in the framework of a sustainable development. Energy thus becomes the key issue in developing circular economy or sustainable development societies [9]. The term 'circular economy' often is misunderstood as a kind of recycling society. Energy question must be taken into account. Firstly, it is linked to use of natural resources, i.e. fossil energy. Secondly, the use of fossil energy leads to major impacts on the environment, because greenhouse gas emissions are being generated $\left(\mathrm{CO}_{2}\right.$, $\mathrm{SO}_{2}, \mathrm{NO}_{\mathrm{x}}$ etc.). Thirdly, the extraction and further use of nonenergetic resources (e.g. steel, cement, etc) also require the use of energy. Aside from resources and waste problems the sustainable availability of energy is the key issue for a circular economy. Therefore, every state must develop a strategy for sustainable energy supply regarding the implementation of circular economy. In that case energy saving and renewable energy technologies become a key issue of circular economy societies. Based on the energy sector development general conclusions regarding the global consumption of natural resources can be carried out.

Countries are implementing different policies to meet the $\mathrm{CO}_{2}$ reductions regarding the Kyoto protocol. It is carried out as a complex strategy covering different policies - energy savings policy, renewable energy policy, other greenhouse gases policy and other policies. This is a good example of whole system striving to reach the common goal.

Tools and strategies to implement circular economy in national and global scale:

- Economic tools: reduce current subsidies and incentives, which encourage the use of virgin raw materials; taking steps to create economic inducements for recycling and reuse; using renewable resources;

- Informational and technical innovations might also be effective;

- New regulatory strategies may be needed [9].

Fig. 2 shows status of material flow policy in the wider environmental policy context. Environmental policy includes soil, emissions, climate, biodiversity and materials policies, which are reflecting the main challenges the world is facing nowadays and implementation of these policies is crucial aspect of meeting the sustainable development goals regarding the circular economy concept.

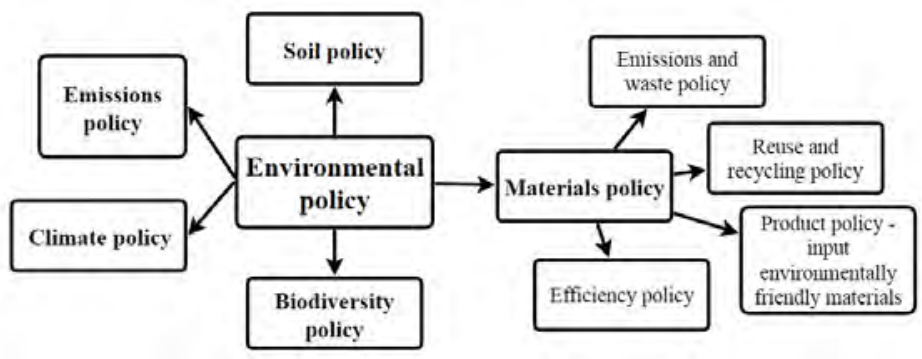

Fig. 2. Status of material flow policy in the wider environmental policy context [9].

Effective, intelligent and profitable raw material management is crucial for implementation of circular economy concept. It can be promoted by focusing not only on quantity, but also on quality and value; by reducing our dependency on non-renewable, critical raw materials and by reducing the rates of wastage and pollution. One way to achieve this is by designing products and services for long-term use, with a focus on reducing a loss in value as much as possible. This will save costs and create new jobs. It would be good for the environment and for the economy. However, it is a timeconsuming, complex process in which involved sides join efforts to innovate and experiment striving to think and work in terms of circularity. The implementation and development of circular economy requires synergy of action, knowledge, social aspects and investments [4].

Since 2011, Netherlands has been applying the 'Green Deal' approach. Green Deals are voluntary agreements between various parties working together to increase innovation and sustainability. The main findings of Green Deal program are:

- the Green Deal approach has added value for the process of green innovation;

- other policies remain necessary for the large-scale rollout of green innovations;

- Green Deals do not automatically benefit the environment;

- even when environmental benefits are plausible, more ambitious targets would be feasible [10].

Current Green Deals are mainly aimed at recycling, but as stated previously at least the energy aspects should be taken into account. That being said, challenging parties that primarily focus on recycling materials to develop higher priority activities might be a good motion towards implementation of circular economy. In addition, all the goals and targets, for example, decrease in $\mathrm{CO}_{2}$ emissions, should be measurable [10].

Relations regarding agriculture, forestry, climate, water management and energy between economies are ilustrated in Fig. 3. The highest synergy is identified between green economy and circular economy, which can provide sustainable development in an urban environment and rural areas. Additionally, all of these relations are part of geoeconomics. 


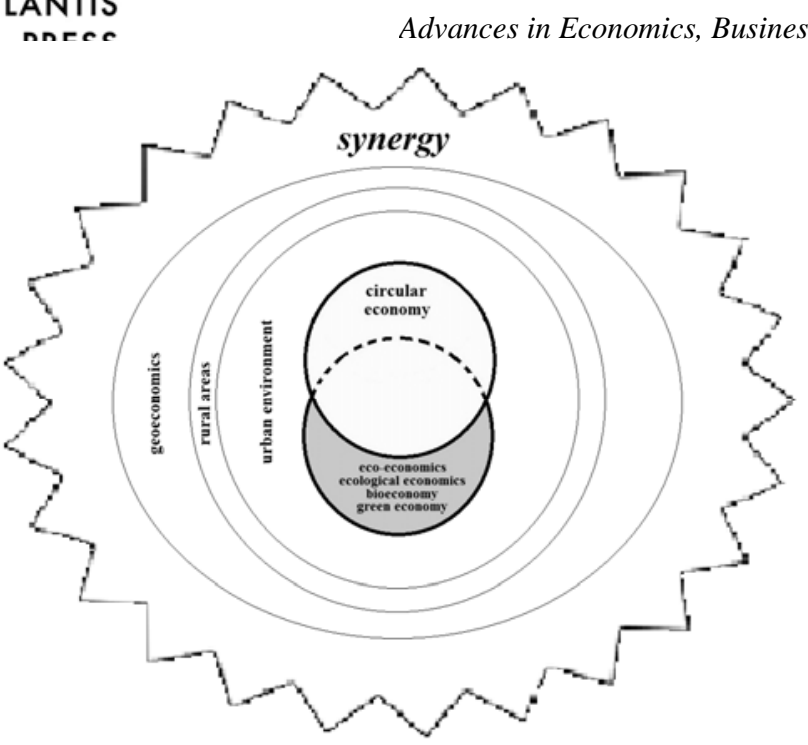

Fig. 3. The synergy between the concepts of green economies and circular economy [11].

Regarding the Fig. 3 it is crucial that society adapts the new - circular approach to the economy - and it is challenging to get 'easy living' society thinking sustainably and implementing and adapting changes regarding the circular economy. It obviously requires greater effort from each individual worldwide compared to linear approach, for example, buying products with recyclable packaging, sorting waste, supporting renewable energy sources etc.

Circular thinking can be integrated into society through consumption, meaning that products should become circular. For example, footwear manufacturer 'Timberland' launched a line of sneakers and boots whose fabric is made from recycled bottles from Haiti [12ך. Global companies with similar actions can force the change in implementing circular economy in our daily life, but most of them have a priority of making greater revenues. So, transformation to a sustainable long-run mind-set is needed. And governments could create a good impact on this situation by supporting companies that implement circular approach to the manufacturing.

\section{CONCLUSIONS}

The circular economy has a characteristic for a positive effect not only on a separate country environment but also cross-borders directly and indirectly impacting living environment and life quality of society. While many facets of the circular economies seem like predictions for a far future, innovative enterprises and individuals are already implementing analogue strategies to bring these economic principles to life. More global organisations dedicate their resources to the principles of circular economy. These principles will become universal across all industries worldwide. Even though circular economy concept offers several benefits and examples of synergy effect, transition to circular economics is postponed for an undefined time period. Additionally, global enterprises with a high influence on public opinion are not yet able to become sufficient impulse for change. Many people primarily seek short-term goals with less evaluation on long-term consequences, as the primary objectives are defined by an artificially maintained consumer concept to 'live easy'. There is a challenge to change the mindset of society and to provide that there are many chances for success and benefits in the concept of circular economy. And it is still being an open issue.

\section{REFERENCES}

[1] H.I. Ansoff, Corporate strategy, revised edition, New York: Penguin Books, 1987, pp. 288.

[2] New World Encyclopedia. 2018. Retrieved 12.07.2018 from http://www.newworldencyclopedia.org/entry/Synergy

[3] Encyclopædia Britannica, 2018. Retrieved 12.07.2018. from http://www.britannica.com/

[4] Government of Netherlands, National Agreement on the Circular Economy: Letter of intent to develop transition agendas for the Circular Economy together, 2017.

[5] E. MacArthur, "Towards the circular economy, " J. Ind. Ecol, pp. 23-44, 2013.

[6] K.E. Boulding, "The Economics of the Coming Spaceship Earth," In H. Jarrett (Ed.), Environmental Quality Issues in a Growing Economy, 1966, pp. 3-14.

[7] R. Balanay and A. Halog, "Charting policy directions for mining's sustainability with circular economy, " Recycling, vol. 1(2), pp. 219-231, 2016.

[8] W. Visser, "Synergy: The Driver of Integrated Value in the New Nexus Economy, " Huffpost, 10 Apr 2017.

[9] P. Heck, Circular Economy related international practices and policy trends: Current situation and practices on sustainable production and consumption and international Circular Economy development policy summary and analysis, Environmental Campus Birkenfeld, 2006, pp. 108.

[10] J. Ganzevles, J. Potting, and A. Hanemaaijer, Evaluation of Green Deals for a Circular Economy. Hague: PBL Netherlands Environmental Assessment Agency, 2017, pp. 46.

[11] J. Zvirgzdin̦š, K. Plotka, and S. Geipele, "Eco-Economics in Cities and Rural Areas, " Baltic Journal of Real Estate Economics and Construction Management, vol. 6, pp. 88-99, 2018.

[12] A. Khalamayzer, "8 ripple effects of the circular economy in 2017," 2017. Retrieved 12.07.2018 from https:/www.greenbiz.com/article/8ripple-effects-circular-economy-2017. 